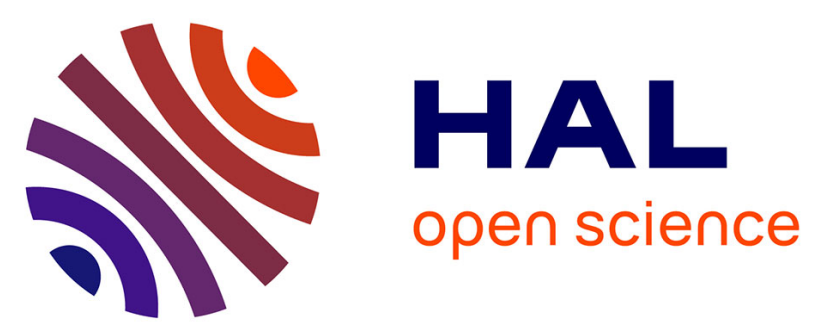

\title{
Evidence of a link between resting energy expenditure and bone remodelling, glucose homeostasis and adipokine variations in adolescent girls with anorexia nervosa
}

Laurent Maïmoun, S. Guillaume, P. Lefebvre, P. Philibert, H. Bertet, M.C. Picot, L. Gaspari, F. Paris, M. Seneque, A.-M. Dupuys, et al.

\section{To cite this version:}

Laurent Maïmoun, S. Guillaume, P. Lefebvre, P. Philibert, H. Bertet, et al.. Evidence of a link between resting energy expenditure and bone remodelling, glucose homeostasis and adipokine variations in adolescent girls with anorexia nervosa. Osteoporosis International, 2016, 27 (1), pp.135 - 146. 10.1007/s00198-015-3223-x . hal-01800536

\section{HAL Id: hal-01800536 \\ https://hal.umontpellier.fr/hal-01800536}

Submitted on 6 Dec 2019

HAL is a multi-disciplinary open access archive for the deposit and dissemination of scientific research documents, whether they are published or not. The documents may come from teaching and research institutions in France or abroad, or from public or private research centers.
L'archive ouverte pluridisciplinaire HAL, est destinée au dépôt et à la diffusion de documents scientifiques de niveau recherche, publiés ou non, émanant des établissements d'enseignement et de recherche français ou étrangers, des laboratoires publics ou privés. 
markers of bone formation, glucose, insulin, HOMA-IR, leptin and IGF-1 and negatively correlated with the bone resorption marker and sOB-R. Biological parameters, aBMD excepted, appeared more affected by the weight variation in the last 6 months than by the disease duration.

Conclusions The strong interrelationships between $\mathrm{REE}_{\mathrm{m}}$ and bone remodelling, glucose homeostasis and adipokines underscore the importance of preventing energy deficiency to limit short- and long-term bone demineralisation and hormonal alterations in AN patients.

Keywords Anorexia nervosa - Bone remodelling · Insulin · Leptin $\cdot$ Resting energy expenditure $\cdot$ Undercarboxylated osteocalcin

\section{Introduction}

A recent hypothesis suggested that bone remodelling is energetically costly for the rest of the body and may therefore be affected by the energy disposal of the organism [1, 2]. Moreover, based on experimental studies, bone is now considered to be an endocrine organ that contributes to the regulation of glucose metabolism and energy expenditure [3,4]. Murine knockout models (Ocn-/-) have clearly shown that osteocalcin (OC), a protein specifically secreted by osteoblasts, is involved in this process. When OC is undercarboxylated (ucOC), its avidity for hydroxyapatite is reduced and this favours its release into the systemic circulation $[3,5]$ where it stimulates $\beta$ cell proliferation, insulin synthesis, insulin secretion, sensitivity to insulin in peripheral tissues and subsequent energy expenditure [3,5]. OC also regulates fat tissue directly by reducing adipocyte number and triglyceride synthesis and increasing the expression of adiponectin and its target genes in white fat [6] and indirectly by increasing energy expenditure through modulating mitochondrial biogenesis in the muscle [3]. OC is further known to increase the expression of genes involved in brown tissue thermogenesis [6]. In humans, proof of this concept is limited, although an association between glucose metabolism and both total and undercarboxylated $\mathrm{OC}$ has been demonstrated by the negative correlation of the two forms of $\mathrm{OC}$ concentration with glucose levels and the degree of insulin resistance, conversely to the positive correlation with insulin secretion and adiponectin concentrations [7-9].

The hypothesised link between energy status and bone remodelling in humans is further supported by the observations of low bone mass acquisition in patients with anorexia nervosa (AN), who have a subsequently higher fracture risk [10-12] and the increased bone mass in young obese individuals [13]. In this context, our group and others have reported in AN patients positive correlations of nutritional markers like weight, body mass index, body fat mass and IGF-1 with the markers of bone formation and negative correlations with the markers of bone resorption [11, 14]. Moreover, Hotta et al. [14] confirmed an alteration in bone remodelling only in patients with a BMI below $16.5 \mathrm{~kg} / \mathrm{m}^{2}$, while values were approximately normal in those with a BMI between 16.5 and $18.5 \mathrm{~kg} / \mathrm{m}^{2}$. These findings suggest that the degree of altered bone remodelling depends on the severity of undernutrition and thus the degree of energy deprivation. Recent data demonstrated that resting energy expenditure measured $\left(\mathrm{REE}_{\mathrm{m}}\right)$ by calorimetry was lower in chronic AN than in controls and this was associated with a significantly reduced metabolic rate of fat-free mass [15].

Leptin, an adipocyte-derived hormone, is a potential link between energy status and bone metabolism not only because it inhibits appetite and favours energy expenditure [16], but also because it has a powerful central action of inhibiting bone mass accrual by inhibiting serotonin synthesis [17-19].

Since puberty is the crucial period for bone mass acquisition [20], an impairment in the acquisition of peak bone mass may increase the risk of osteoporosis later in life [21]. Better knowledge of the mechanisms that regulate bone metabolism in cases of undernutrition would be helpful to develop countermeasures.

The aim of the study was to investigate the relationship between energy metabolism measured by calorimetry and bone status in a condition of dramatic undernutrition in adolescents and young women with AN. Moreover, the potential interactions between energy status, bone metabolism, glucose homeostasis and adipose tissue-derived hormones were concomitantly evaluated.

\section{Subjects and method}

Study approval was obtained from the Regional Research Ethics Committee (Comité de Protection des Personnes SudMediterranee IV, Montpellier, France; reference: 1102 03), and permission for the clinical trials was granted by the French Medicines and Health Care Products Regulatory Agency (Agence Française de Securite Sanitaire des Produits de Santé; AFSSAPS). Written informed consent was obtained from all participants and their parents when the volunteers were minors.

\section{Subjects}

A total of 100 adolescent and young women with ages ranging from 14.4 to 23.8 years (mean 18.1 \pm 2.3 ) were enrolled in this study. Fifty of them had been diagnosed with anorexia nervosa. Patients were consecutively recruited from the Endocrinology Department at Montpellier University Hospital (France) in 2009-2012. They fulfilled the criteria for the diagnosis of AN as defined by the Diagnostic and Statistical 
Manual of Mental Disorders (DSM) IV, i.e. amenorrhoea, body mass index (BMI) $<18 \mathrm{~kg} / \mathrm{m}^{2}$, fear of gaining weight and alteration in body size perception (American Psychiatric Association, 1994). Only patients with the pure restrictive form of AN were included in this study to limit potential bias due to a mix of the eating/purging and pure restrictive AN types. The control group (CON) was recruited from advertisements in local newspapers and from the staff and students in the Departments of Nuclear Medicine, Endocrinology and Psychiatry of Lapeyronie Hospital, CHRU Montpellier. The group was composed of 50 normal weight healthy adolescent and young women with $18<\mathrm{BMI}<25 \mathrm{~kg} / \mathrm{m}^{2}$. None of them had any history of eating disorders or other psychiatric illness as determined by the SCOFF questionnaire [22] and the Mini International Neuropsychiatric Interview [23]. All the controls presented normal menstrual cycles and performed only leisure physical activities. Neither control subjects nor anorexic patients presented with primary amenorrhoea or had impaired glucose regulation or diabetes mellitus or were taking any medications known to affect glucose or bone metabolism. Some of the participants have been described elsewhere [11].

\section{Methods}

This study followed a case-control design and has been described in detail elsewhere [11]. Standing height was measured with a stadiometer to the nearest $0.1 \mathrm{~cm}$. Weight was determined using a weight scale with a precision of $0.1 \mathrm{~kg}$. BMI was calculated as weight $(\mathrm{kg})$ divided by the square of height $(\mathrm{m})$. Height standard deviation score (height SDS) and weight standard deviation score (weight SDS) were calculated according to the French standard curves. Moreover, weight history was self-reported by each patient.

\section{Medical and menstrual histories}

Each subject or her parents responded to a medical questionnaire designed to assess the general medical and menstrual (age of menarche, menstrual function) and disease histories (age of $\mathrm{AN}$ onset, duration of $\mathrm{AN}$ and weight variations).

\section{Resting energy expenditure measurements}

Measured resting energy expenditure $\left(\mathrm{REE}_{\mathrm{m}}\right)$ was assessed over a period of at least $30 \mathrm{~min}$ by indirect calorimetry (Quark RMR, Cosmed, Rome, Italy) after an overnight fast in the patients with AN.

Predicted REE values $\left(\%\right.$; $\left.R E E_{p}\right)$ were calculated for $A N$ and $\mathrm{CON}$ from the equation of Harris and Benedict modified by Roza and Shizgal [24] as follows: $\mathrm{REE}_{\mathrm{p}}=667.051+$ $9.74 \times($ weight $)+1.729 \times($ height $)-4.737 \times($ age $)$.

\section{Assays}

Blood samples $(25 \mathrm{ml})$ were collected in the morning $(0830$ 0930 hours) in chilled sterile tubes by standard venipuncture technique. The samples were allowed to clot at room temperature and were then centrifuged at $2500 \mathrm{rpm}$ for $10 \mathrm{~min}$ at $4{ }^{\circ} \mathrm{C}$. Plasma samples were stored at $-80^{\circ} \mathrm{C}$ until analysis. All samples were run in duplicate, and to reduce inter-assay variation, the plasma samples were analysed in a single session. The date of the last menses was not recorded for CON, and hormonal values were thus obtained at an unsynchronised menstrual stage. Serum OC, undercarboxylated osteocalcin (ucOC), procollagen type I $N$-terminal propeptide (PINP), type I-C telopeptide breakdown products (CTX), insulin, leptin, soluble leptin receptor (sOB-R), adiponectin, insulin-like growth factor (IGF-1) and insulin-like growth factor binding protein (IGFBP-3) were evaluated.

OC, PINP, CTX and insulin were assayed by Cobas 6000 (Roche Diagnostic, Mannheim, Germany). The inter- and intra-assay coefficients of variations (CVs) for the three latter parameters were lower than $7 \%$.

The intra- and inter-assay CVs for leptin were, respectively, $<5$ and $<7.6 \%$ (Mediagnost GmbH, Reutlingen, Germany). sOB-R concentration was measured with an ELISA kit (Biovendor, Brno, Czech Republic). Sensitivity was 0.4 U/ $\mathrm{ml}$, and the intra- and inter-assay variability was 4.4 and 7.2, respectively. The free leptin index (FLI) was calculated as the ratio of leptin to sOB-R [25]. Adiponectin (TECOmedical AG, Sissach, Switzerland) and ucOC (Takara Bio, Inc., Otsu, Japan) concentrations were measured with the ELISA kit, and the intra- and inter-assay variability was $<5$ and $<7 \%$, respectively.

The intra- and inter-assay CVs for IGF-1 (Immulite 2000® IGF-1, Siemens Healthcare Diagnostics) and IGFBP-3 (Immulite 2000® IGFBP-3, Siemens Healthcare Diagnostics) were lower than $6 \%$. The IGF-1/IGFBP-3 ratio was calculated as follows: (IGF-1/IGFBP-3) $\times 100$.

For the biological parameters, the CVs for the intra- and inter-assay variations were given by the manufacturer. Homeostasis model assessment (HOMA) of insulin resistance (IR) was defined as (fasting plasma insulin $[\mu \mathrm{U} / \mathrm{ml}] \times$ fasting plasma glucose $[\mathrm{mmol} / 1]) / 22.5$.

\section{Areal bone mineral density, body fat and fat-free soft tissues}

DXA (Hologic QDR-4500A, Hologic, Inc., Waltham, MA) measured the areal bone mineral density (aBMD; $\mathrm{g} / \mathrm{cm}^{2}$ ) of the whole body and at specific bone sites: the anteroposterior lumbar spine (L1-L4), the dominant arm radius, hip and femoral neck (FN). The soft tissue body composition (fat mass $[\mathrm{FM}, \mathrm{kg}]$, percentage of body fat mass [\% FM] and fat-free soft tissue [FFST, kg]) was derived from the whole body scan. 
All scanning and analyses were performed by the same operator to ensure consistency, after following standard quality control procedures. Quality control for DXA was checked daily by scanning a lumbar spine phantom consisting of calcium hydroxyapatite embedded in a cube of thermoplastic resin (DPA/QDR-1; Hologic x-caliber anthropometrical spine phantom). The CVs given by the manufacturer were $0.8 \%$ for spine and radius, $1.1 \%$ at the hip and $<1 \%$ for FFST and FM.

\section{Statistical analysis}

The study population was described with means and standard deviations (SD) for quantitative variables and with frequencies for qualitative variables. The continuous variable distributions were tested with the Shapiro-Wilk statistic. Quantitative variables were compared with the parametric Student's $t$ test when the distribution was Gaussian and with the MannWhitney test otherwise. To summarise the relationships between continuous variables, a Pearson or Spearman coefficient correlation was used.

Linear regression analyses were carried out to identify the factors associated with $\mathrm{REE}_{\mathrm{m}}$. Variables with a $p$ value $\leq 0.2$ in the univariate analysis were introduced in the multivariate analysis. The final model was determined using a backward selection with a removal level of 0.05 . The absence of collinearity between variables was verified with variance inflation factors. To test the validity of the model, the normality of residues was tested with the Shapiro-Wilk test.

The two-sided significance level was 0.05 . The statistical analysis was conducted at the Department of Epidemiology and Biostatistics, University Hospital of Montpellier, France, with SAS version 9 (SAS Institute, Cary, NC, USA).

\section{Results}

\section{Anthropometric and gynaecological characteristics}

Subject characteristics are shown in Table 1 . The age distribution ranged from 14.5 to 23.9 years, with a mean age of $18.0 \pm$ 2.1 and $18.1 \pm 2.7$ years for $\mathrm{AN}$ and $\mathrm{CON}$, respectively. As expected, due to undernutrition, body weight, BMI, \% body fat, total FM $(\mathrm{kg})$ and FFST were markedly lower in AN patients compared with CON $(p<0.001)$. When weight SDS and height SDS were calculated according to the French standard curves, AN also presented low values for weight $(-1.8 \pm$ $0.9 \mathrm{SD})$ and normal values for height $(0.3 \pm 1.1 \mathrm{SD})$. The mean age of onset of AN was $16.0 \pm 1.9$ years (range 13.0 to 21.5 years), and the mean duration was $2.1 \pm 1.8$ years (range 0.5 to 8.2 years).

The age of menarche was not different between groups (12.7 \pm 1.3 and $12.3 \pm 1.4$ for AN and CON, respectively). All patients had secondary amenorrhoea, corresponding to the criteria of DSM IV. Eight patients (16\%) were already taking oral contraceptives when included in the study. Among CON, only minor variations in the duration of menstrual cycles ( $\sim 28$ days) were encountered and $46 \%$ of them were taking oral contraceptives (23 of 50).

\section{Bone mineral density, hormonal and biochemical parameters}

$\mathrm{aBMD}$ at all bone sites was significantly lower (ranging from $p<0.01$ to $p<0.001$ ) in patients with AN compared with CON (whole body $[-4.7 \%]$, lumbar spine $[-14.8 \%]$, hip $[-15.6 \%]$, FN $[-14.9 \%]$ and radius $[-4.6 \%]$ ) (Table 2).

Regarding bone remodelling, adolescents and young women with AN presented lower mean values for markers of bone formation (OC: $-37.2 \%, p<0.001$ and PINP: $-44.8 \%$, $p<0.001)$ and a higher mean value for the bone resorption marker (CTX: $+55.2 \%, p<0.001)$. Calcium $(+2.4 \%$, $p<0.05)$ and phosphorus $(+8.3 \%, p<0.001)$ concentrations were also significantly higher in AN patients. Patients taking oral contraceptives pills (OCPs) presented lower CTX, but aBMD values did not differ between the two groups.

Fasting serum leptin levels and FLI were significantly and severely decreased ( -86.8 and $-92.2 \%$, respectively, $p<0.001$ ) in patients with AN, whereas fasting serum sOB$\mathrm{R}$ and adiponectin levels were significantly higher $(+65$ and + $58.3 \%$, respectively, $p<0.001$ ) (Table 2 ). ucOC, glucose, insulin, HOMA-IR, IGF-1 and IGF-1/IGFBP-3 were significantly reduced (all parameters $p<0.001$ ) in AN patients and the IGFBP-3 level tended to be lower $(p=0.07)$ compared with CON.

The values of $\operatorname{REE}_{\mathrm{m}}(992.3 \pm 154.8)$ indicated hypometabolism in AN. REE p was significantly lower $(p<0.001 ;-10.9 \%)$ in AN patients compared with CON. A mean significant difference of $284.5 \pm 132.9 \mathrm{kcal} /$ day was observed between $\mathrm{REE}_{\mathrm{m}}$ and $\mathrm{REE}_{\mathrm{p}}$ in $\mathrm{AN}$, which corresponded to an average variation of $31.4 \%$.

\section{Correlations between REE and various parameters}

The correlations between $\mathrm{REE}_{\mathrm{m}}$ or $\mathrm{REE}_{\mathrm{p}}$ and the various clinical, anthropometric and biological parameters are presented in Table $3 . \mathrm{REE}_{\mathrm{m}}$ in the AN patients was significantly and positively correlated with weight, BMI, WB FM, WB FFST, PINP, OC, glucose, insulin, HOMA-IR, leptin, FLI, IGF-1 and IGFBP-3 and negatively with CTX and sOB-R. Conversely, $\mathrm{REE}_{\mathrm{p}}$ appeared more highly correlated with aBMD and less correlated with bone remodelling markers and glucose homeostasis parameters than $\mathrm{REE}_{\mathrm{m}}$. $\mathrm{REE}_{\mathrm{p}}$ in CON was significantly and positively correlated with weight, BMI, L1L4 aBMD, WB FM, WB FFST, leptin and FLI and negatively with OC. 
Table 1 Clinical characteristics of adolescent and young adult women with anorexia nervosa and controls

\begin{tabular}{llll}
\hline Parameters & Controls & Patients with AN & $p$ value \\
\hline Number of subjects & $n=50$ & $n=50$ & 0.69 \\
Age, years & $18.1 \pm 2.7$ & $18.0 \pm 2.1$ & $<0.001$ \\
Anthropometric data & & $42.2 \pm 5.4$ & $<0.001$ \\
$\quad$ Weight, kg & $58.0 \pm 8.1$ & $-1.8 \pm 0.9$ & 0.26 \\
Weight, SDS & $0.8 \pm 1.2$ & $164.1 \pm 5.6$ & 0.22 \\
Height, cm & $165.5 \pm 6.0$ & $0.3 \pm 1.1$ & $<0.001$ \\
Height, SDS & $0.6 \pm 1.1$ & $15.7 \pm 1.8$ & $<0.001$ \\
BMI, kg m ${ }^{-2}$ & $21.1 \pm 2.2$ & $15.9 \pm 5.6$ & $<0.001$ \\
WB fat mass, \% & $26.5 \pm 5.6$ & $6.9 \pm 2.8$ & $<0.001$ \\
WB fat mass, kg & $15.7 \pm 5.1$ & $33.7 \pm 4.1$ & $<0.01$ \\
WB fat-free soft tissue, kg & $40.3 \pm 4.0$ & & $<0.001$ \\
Characteristics of the pathology & & $16.0 \pm 1.9$ & $2.1 \pm 1.8$ \\
Age of AN onset, years & - & & $12.7 \pm 1.3$ \\
Duration of AN, years & - & $50(100 \%)$ & $12.9 \pm 12.8$ \\
Gynaecological data & $12.3 \pm 1.4$ & $8(16 \%)$ & \\
Age of menarche, years & $11(22 \%)$ & & \\
Menstrual disorders, $n$ (\%) & - & & \\
Duration of amenorrhoea ${ }^{\mathrm{a}}$, months & & & \\
Contraceptives, $n$ (\%) & & &
\end{tabular}

Values are presented as mean \pm SD. Controls presented only minor alteration in the duration of menstrual cycles ( $\sim 28$ days)

$B M I$ body mass index, $S D S$ standard deviation score, $W B$ whole body

${ }^{a}$ Duration of amenorrhoea was only reported in patients not taking contraceptives
In the multivariate model, increases in WB FFST $(p<0.01)$, PINP $(p<0.01)$ and HOMA IR $(p<0.01)$ and a decrease in CTX $(p<0.001)$ were associated with an increase of $\mathrm{REE}_{\mathrm{m}}$. These variables explained respectively $14,13,19$ and $21 \%$ of the $\mathrm{REE}_{\mathrm{m}}$ variance, with a total explained variance of $67 \%$.

\section{Correlations between aBMD and clinical and biological data}

Briefly, aBMD in patients was positively correlated $(p<0.05$ to $p<0.01)$ at all bone sites, radius excepted, with weight; aBMD at WB and L1-L4 was positively correlated $(r=0.33$ and $r=0.34 ; p<0.05$ ) with WB FFST; and aBMD at L1-L4 and hip was positively correlated with IGFBP-3 $(r=0.35$ and $r=0.31, p<0.05)$. Moreover, the age of AN onset was positively correlated with aBMD at radius $(r=0.27, p<0.05)$. Negative correlations were observed between the duration of AN and aBMD at hip $(r=-0.39, p<0.01)$ and between the duration of amenorrhoea and aBMD at L1-L4 and hip $(r=-0.31$ and $r=-0.38 ; p<0.05)$. aBMD at WB was negatively correlated with PINP and OC ( $r=-0.37$ and $r=-0.31, p<0.01$ and $p<0.05)$, aBMD at L1-L4 and hip was negatively correlated with adiponectin $(r=-0.41$ and $r=-0.38, p<0.01)$ and aBMD at radius was negatively correlated with CTX $(r=-0.27$, $p<0.05)$ and uOC $(-0.31 ; p<0.05)$. A positive correlation $(r=0.27, p<0.05)$ was found between aBMD at L1-L4 and HOMA-IR.

\section{Correlations between bone markers, adipokines, glucose homeostasis and growth factors}

Briefly, PINP and OC were positively and strongly correlated with leptin ( $r=0.56$ for both, $p<0.001$ ), and these three biological parameters were positively correlated with insulin, HOMA-IR, FLI and IGF-1 and negatively with sOB-R. OC and leptin were positively correlated with glucose $(r=0.30$ and $r=0.42, p<0.05)$ and IGFBP-3 $(r=0.40 ; p<0.01$ and $r=0.56$; $p<0.001)$. CTX was negatively correlated only with FLI ( $r=$ $-0.33, p<0.05)$.

\section{Effects of the duration of anorexia nervosa}

No correlation was found between the duration of the disease and $\mathrm{REE}_{\mathrm{m}}, \mathrm{REE}_{\mathrm{p}}$, bone parameters, glucose metabolism or anthropometric factors. A negative correlation was found only between the duration of AN and aBMD at the hip ( $r=-0.39$; $p<0.01)$ and the CTX level $(r=-0.3, p=0.03)$. Nevertheless, in order to discriminate patients with relatively 'acute' or 'chronic' disease, the patients were subdivided into two groups according to the median (1.52 years) of the disease 
Table 2 Areal bone mineral density at various bone sites and biological variables in patients with anorexia nervosa and controls

\begin{tabular}{|c|c|c|c|c|}
\hline Parameters & Controls & Patients with AN & Difference, $\%^{\mathrm{a}}$ & $p$ value \\
\hline \multicolumn{5}{|c|}{ Areal Bone Mineral Density $\left(\mathrm{g} \mathrm{cm}^{-2}\right)$} \\
\hline Whole body & $1.076 \pm 0.075$ & $1.025 \pm 0.089$ & -4.7 & $<0.01$ \\
\hline Lumbar spine & $0.990 \pm 0.115$ & $0.843 \pm 0.101$ & -14.8 & $<0.001$ \\
\hline Hip & $0.965 \pm 0.103$ & $0.813 \pm 0.123$ & -15.6 & $<0.001$ \\
\hline $\mathrm{FN}$ & $0.876 \pm 0.102$ & $0.745 \pm 0.118$ & -14.9 & $<0.001$ \\
\hline Radius & $0.542 \pm 0.031$ & $0.517 \pm 0.045$ & -4.6 & $<0.01$ \\
\hline \multicolumn{5}{|l|}{ Biological parameters } \\
\hline $\mathrm{Ca}, \mathrm{mmol} / \mathrm{l}$ & $2.45 \pm 0.13$ & $2.51 \pm 0.12$ & +2.4 & $<0.05$ \\
\hline $\mathrm{P}, \mathrm{mmol} / \mathrm{l}$ & $1.20 \pm 0.16$ & $1.30 \pm 0.14$ & +8.3 & $<0.001$ \\
\hline CTX, ng/ml & $0.580 \pm 0.210$ & $0.895 \pm 0.365$ & +55.2 & $<0.001$ \\
\hline PINP, ng/ml & $108.9 \pm 83.9$ & $60.2 \pm 35.6$ & -44.8 & $<0.001$ \\
\hline $\mathrm{OC}, \mathrm{ng} / \mathrm{ml}$ & $39.0 \pm 20.1$ & $24.5 \pm 10.5$ & -37.2 & $<0.001$ \\
\hline $\mathrm{ucOC}, \mathrm{ng} / \mathrm{ml}$ & $6.2 \pm 3.7$ & $2.4 \pm 2.6$ & -61.3 & $<0.001$ \\
\hline Glucose, $\mathrm{mmol} / \mathrm{l}$ & $4.69 \pm 0.55$ & $4.16 \pm 0.79$ & -11.3 & $<0.001$ \\
\hline Insulin, $\mu \mathrm{U} / \mathrm{ml}$ & $10.7 \pm 3.7$ & $4.8 \pm 3.3$ & -55.1 & $<0.001$ \\
\hline HOMA-IR & $2.24 \pm 0.88$ & $0.92 \pm 0.70$ & -59.1 & $<0.001$ \\
\hline Leptin, ng/ml & $9.61 \pm 5.95$ & $1.27 \pm 1.47$ & -86.8 & $<0.001$ \\
\hline $\mathrm{sOB}-\mathrm{R}, \mathrm{ng} / \mathrm{ml}$ & $24.0 \pm 8.5$ & $39.6 \pm 12.1$ & +65.0 & $<0.001$ \\
\hline FLI & $0.51 \pm 0.48$ & $0.04 \pm 0.05$ & -92.2 & $<0.001$ \\
\hline Adiponectin, $\mu \mathrm{g} / \mathrm{ml}$ & $12.0 \pm 5.8$ & $19.0 \pm 7.7$ & +58.3 & $<0.001$ \\
\hline $\mathrm{IGF}-1, \mathrm{ng} / \mathrm{ml}$ & $317.0 \pm 109.3$ & $183.8 \pm 76.1$ & -42.0 & $<0.001$ \\
\hline IGFBP-3, ng/ml & $5420.7 \pm 1094.1$ & $5005.7 \pm 1178.8$ & -7.7 & 0.07 \\
\hline IGF-1/IGFBP-3 ratio & $5.9 \pm 1.9$ & $3.6 \pm 1.1$ & -39.0 & $<0.001$ \\
\hline \multicolumn{5}{|l|}{ Energy metabolism } \\
\hline $\mathrm{REE}_{\mathrm{m}}, \mathrm{kcal} / \mathrm{day}$ & - & $992.3 \pm 154.8$ & - & - \\
\hline REEp, kcal/day & $1432.5 \pm 83.7$ & $1276.8 \pm 57.2$ & -10.9 & $<0.001$ \\
\hline Predicted REE values, $\%$ & - & $-22.4 \pm 10.7$ & - & - \\
\hline
\end{tabular}

Values are presented as mean $\pm \mathrm{SD}$

$F N$ femoral neck, $C a$ calcium, $P$ phosphorus, $C T X$ type I-C telopeptide breakdown products, $P I N P$ procollagen type I N-terminal propeptide, $O C$ osteocalcin, ucOC: undercarboxylated OC, HOMA-IR homeostasis model assessment of insulin resistance, $s O B-R$ soluble leptin receptor, $F L I$ free leptin index defined as leptin/sOB-R ratio, $I G F-1$ insulin-like growth factor-1, IGFBP-3 insulin-like growth factor binding protein-3, $R E E_{m}$ resting energy expenditure measured by calorimetry, $R E E_{p}$ resting energy expenditure predicted from the equation of Harris and Benedict modified by Roza and Shizgal (22)

${ }^{\text {a }}$ Difference $=(($ mean AN - mean CONT $) /$ meanCONT $) * 100$ duration. Table 4 shows the significantly different parameters of the acute and chronic groups. Age, anorexia nervosa and amenorrhoea durations were greater in chronic patients, whereas aBMD at FN was significantly lower $(p=0.04)$ and tended to be lower at L1-L4 and hip $(p=0.07)$ than in the acute group. No difference between AN groups was demonstrated for anthropometric (weight, BMI, WB FM and WB FFST) or biological data (data not shown).

\section{Effects of weight variation}

In addition to the disease duration, it is likely that the phase of the disease (healing or not), as defined by a gain or loss in weight, influenced the parameters. To test this hypothesis, patients were again subdivided on the basis of the weight change in the last 6 months. Table 5 shows the difference between patients who presented weight gain $(n=10$, mean $3.7 \pm 1.6 \mathrm{~kg}$ ) and those who presented significant weight loss $(n=34$, mean $-7.1 \pm 3.9 \mathrm{~kg}$ ). The two groups of patients had received the same medical care (psychological and nutritional management). In two patients, the weight at 6 months was not recorded, and in four patients, the variation in weight during this period was less than $1 \mathrm{~kg}$, the minimum considered to be clinical relevant. These six patients were not maintained in the final analysis. The weight 6 months earlier was significantly lower in the weight gain group compared with the weigh loss group. Weight, WB FM, WB FFST and $\mathrm{REE}_{\mathrm{m}}$ were not different between groups; OC, leptin and FLI were higher; and 
Table 3 Correlation analysis between measured and predicted REE and different parameters in patients with $\mathrm{AN}$ and $\mathrm{CON}$

\begin{tabular}{|c|c|c|c|}
\hline Parameters & Patients with AN REE $\mathrm{m}_{\mathrm{m}}$ & Patients with $A N R E_{p}$ & Controls $\mathrm{REE}_{\mathrm{p}}$ \\
\hline Weight, $\mathrm{kg}$ & $0.59 * * *$ & ${ }_{-}^{a}$ & ${ }^{\mathrm{a}}$ \\
\hline BMI, $\mathrm{kg} / \mathrm{m}^{2}$ & $0.64 * * *$ & $-^{\mathrm{a}}$ & $-{ }^{\mathrm{a}}$ \\
\hline Duration of AN, years & 0.21 & 0.07 & - \\
\hline Amenorrhoea duration, months & -0.004 & -0.03 & - \\
\hline WB aBMD, $\mathrm{g} \mathrm{cm}^{2}$ & -0.01 & $0.33^{*}$ & 0.22 \\
\hline L1-L4 aBMD, g cm ${ }^{2}$ & -0.03 & $0.37 * *$ & $0.38 * *$ \\
\hline hip aBMD, $\mathrm{g} \mathrm{cm}^{2}$ & -0.01 & $0.28^{*}$ & 0.19 \\
\hline $\mathrm{FN}$ aBMD, $\mathrm{g} \mathrm{cm}^{2}$ & -0.07 & $0.55 * *$ & 0.15 \\
\hline Radius aBMD, $\mathrm{g} \mathrm{cm}^{2}$ & -0.04 & 0.09 & 0.16 \\
\hline WB FM, kg & $0.51 * * *$ & $0.61 * * *$ & $0.88 * * *$ \\
\hline WB FFST, kg & $0.45^{* *}$ & $0.86 * * *$ & $0.83 * * *$ \\
\hline CTX, ng/ml & $-0.46 * * *$ & -0.22 & -0.06 \\
\hline PINP, ng/ml & $0.50 * * *$ & 0.24 & -0.13 \\
\hline $\mathrm{OC}, \mathrm{ng} / \mathrm{ml}$ & $0.47^{* * *}$ & $0.30 *$ & $-0.21^{*}$ \\
\hline $\mathrm{ucOC}, \mathrm{ng} / \mathrm{ml}$ & 0.24 & 0.18 & -0.05 \\
\hline Glucose, $\mathrm{mmol} / \mathrm{l}$ & $0.36^{*}$ & $0.29 *$ & 0.21 \\
\hline Insulin, $\mu \mathrm{U} / \mathrm{ml}$ & $0.46^{* * *}$ & 0.24 & 0.09 \\
\hline HOMA-IR & $0.52 * * *$ & $0.34 *$ & 0.11 \\
\hline Leptin, $\mathrm{ng} / \mathrm{ml}$ & $0.57 * * *$ & $0.46^{* *}$ & $0.56^{* * *}$ \\
\hline $\mathrm{sOB}-\mathrm{R}, \mathrm{ng} / \mathrm{ml}$ & $-0.29 *$ & $-0.38 * *$ & $-0.25(\mathrm{p}=0.09)$ \\
\hline FLI & $0.59 * * *$ & $0.49 * * *$ & $0.52 * * *$ \\
\hline Adiponectin, $\mu \mathrm{g} / \mathrm{ml}$ & 0.04 & -0.10 & -0.27 \\
\hline IGF-1, ng/ml & $0.63 * * *$ & $0.54 * * *$ & 0.22 \\
\hline IGFBP-3, ng/ml & $0.45^{* *}$ & $0.57 * * *$ & 0.18 \\
\hline
\end{tabular}

Data are presented as $r$ (Pearson coefficient correlation) and significant correlation was denoted by $* p<0.05$, $* * p<0.01$ and $* * * p<0.001$

$B M I$ body mass index, $A N$ anorexia nervosa, $W B$ whole body, $a B M D$ areal bone mineral density, $L 1-L 4$ lumbar spine, $F N$ femoral neck, $F M$ fat mass, FFST fat-free soft tissue, CTX type I-C telopeptide breakdown products, PINP procollagen type I N-terminal propeptide, $O C$ osteocalcin, ucOC undercarboxylated OC, HOMA-IR homeostasis model assessment of insulin resistance, $s O B-R$ soluble leptin receptor, $F L I$ free leptin index defined as leptin/sOB-R ratio, $I G F-1$ insulin-like growth factor-1, IGFBP-3 insulin-like growth factor binding protein-3

${ }^{\text {a }}$ Correlations between weight, BMI and REE predicted are not presented because weight and BMI are used in the equation of Roza and Shizgal (24) for the determination of REE predicted
CTX, hip and FN aBMD were lower in the weight gain compared with weight loss group.

\section{Discussion}

In this work, we show that $\mathrm{AN}$ induces several alterations in bone mass acquisition, as well as in body composition and calcium, glucose and energy metabolism. Moreover, we demonstrate for the first time that REE measured by calorimetry provides an accurate reflection of not only the altered body composition, but also the variations in bone remodelling, glucose homeostasis, adipose tissue-derived hormones and growth factor secretion.

Although the impairment in bone mass acquisition is a well-known consequence of AN [10,11,26-28], we highlight here that the deleterious effect of AN begins early and is severe, showing that bone mass at trabecular (lumbar spine) and cortical (femur) sites was reduced by $15 \% 2$ years after AN onset. These results suggest that the clinical management of bone loss should be initiated soon after the time of diagnosis to reduce the impact on peak bone mass and the subsequent risk of future osteoporosis [29]. The most important new finding of this study, however, is the direct and specific link between $\mathrm{REE}_{\mathrm{m}}$ and bone turnover markers. This result was supported by a positive correlation between $\mathrm{REE}_{\mathrm{m}}$ and OC or PINP, markers reflecting bone formation, and the negative correlation between $\mathrm{REE}_{\mathrm{m}}$ and CTX, a marker reflecting bone resorption. The low $\mathrm{REE}_{\mathrm{m}}$ observed in AN patients has been considered as a protective mechanism for limiting the loss of body mass [15], mainly related to a reduction in FFST [30]. Our results strongly suggest that the more $\mathrm{REE}_{\mathrm{m}}$ is reduced, 
Table 4 Comparison between patient groups according to the duration of the pathology

\begin{tabular}{llll}
\hline Parameters & Acute $(n=25)$ & Chronic $(n=25)$ & $p$ value \\
\hline Age, years & $17.2 \pm 1.9$ & $18.9 \pm 2.0$ & $<0.01$ \\
Weight, $\mathrm{kg}$ & $42.0 \pm 6.1$ & $42.5 \pm 4.7$ & 0.74 \\
BMI, $\mathrm{kg} / \mathrm{m}^{2}$ & $15.8 \pm 1.9$ & $15.6 \pm 1.7$ & 0.46 \\
Duration of AN, years & $0.9 \pm 0.3$ & $3.3 \pm 1.9$ & $<0.001$ \\
Amenorrhoea duration, months & $7.5 \pm 5.3$ & $19.9 \pm 16.1$ & $<0.01$ \\
L1-L4 aBMD, g/cm ${ }^{2}$ & $0.868 \pm 0.101$ & $0.817 \pm 0.096$ & 0.07 \\
Hip aBMD, g/cm ${ }^{2}$ & $0.845 \pm 0.130$ & $0.782 \pm 0.110$ & 0.07 \\
FN aBMD, g/cm ${ }^{2}$ & $0.778 \pm 0.125$ & $0.711 \pm 0.103$ & $<0.05$ \\
CTX, ng/ml & $0.950 \pm 0.370$ & $0.840 \pm 0.350$ & 0.31 \\
PINP, ng/ml & $64.3 \pm 37.6$ & $56.2 \pm 33.8$ & 0.50 \\
OC, ng/ml & $25.1 \pm 10.8$ & $23.9 \pm 10.3$ & 0.71 \\
REE, $\mathrm{kcal} /$ day & $978.8 \pm 157.1$ & $1005.9 \pm 154.6$ & 0.54 \\
REE, $\mathrm{kcal} /$ day & $1276.2 \pm 67.0$ & $1277.5 \pm 46.8$ & 0.95 \\
Predicted REE values, $\%$ & $-23.4 \pm 11.1$ & $-21.5 \pm 10.5$ & 0.53 \\
\hline
\end{tabular}

Values are presented as mean $\pm \mathrm{SD}$

Patients with anorexia nervosa were classified in 'acute' and 'chronic' groups based on the median duration of the pathology (1.5 years)

$B M I$ body mass index, $A N$ anorexia nervosa, $a B M D$ areal bone mineral density, $L 1-L 4$ lumbar spine, $F N$ femoral neck, $R E E_{m}$ resting energy expenditure, $R E E_{p}$ resting energy expenditure predicted the more bone turnover is altered in favour of bone resorption. Unfortunately, we were not able to demonstrate the same link between $\mathrm{REE}_{\mathrm{m}}$ and aBMD measured at various bone sites. Although these two sets of data seem divergent, it is likely that bone turnover and bone mass present specific kinetic adaptations and that bone cell activity, like $\mathrm{REE}_{\mathrm{m}}$, is rapidly impacted by severe undernutrition, while bone loss is a slower process that requires more time to be detected by aBMD changes. The subdivision of AN patients according to the duration of the disease allowed us to confirm this hypothesis. Although no difference between acute and chronic phases was demonstrated regarding $\mathrm{REE}_{\mathrm{m}}$ and bone remodelling markers, a greater reduction in aBMD was highlighted in the chronic patients.

In this context of severe undernutrition, what is the link between energy deprivation and bone turnover alteration?

Experimental data demonstrated that a gain-of-function model (Esp-/- mice) of OC was characterised by increased energy expenditure, while the inactivation of OC showed the opposite effect [3]. In addition, OC injections in wild-type mice on a high-fat diet showed an increase in energy expenditure without affecting food intake [31, 32]. In line with these results, the present study demonstrates that in addition to $\mathrm{OC}$, the secretion of ucOC, the only form active on $\beta$ cells [6], is decreased along with $\mathrm{REE}_{\mathrm{m}}$ in $\mathrm{AN}$ patients. In mice lacking the insulin receptor in osteoblasts ( $\operatorname{InsR}_{\mathrm{osb}}{ }^{-1}$ mice), low ucOC levels, glucose intolerance and insulin insensitivity have been reported $[33,34]$, suggesting that insulin signalling in osteoblasts is a determinant factor of osteocalcin bioactivity [35]. Moreover, Ferron et al. [33] demonstrated that insulin inhibits the expression in osteoblasts of the gene encoding for osteoprotegerin (OPG), a cytokine known to suppress osteoclast differentiation. The low insulin levels observed in this work, as well as in a previous study [36], may partly explain the higher circulating OPG levels and the positive correlation between OPG values and the markers of nutritional status previously reported in AN patients [10, 37]. However, the OPG/ sRANKL ratio was also found to be lower in AN, thereby contributing to enhanced bone resorption [37] and acidification of the bone mineral matrix, which in turn may accentuate decarboxylation and thus activate osteocalcin product [33]. The reduced insulin and increased bone resorption in our patients should have resulted in an increase in ucOC values. However, the pool of available OC was decreased and associated with a reduced decarboxylation rate. This was supported by the finding of a higher OC/ucOC ratio in $\mathrm{AN}$ (10.2 for AN and 6.2 for CON; data not shown). The concomitant reductions in OC levels and decarboxylation activity most likely overtook the effects of low insulin and increased resorption activity, which resulted in lower ucOC. In addition, the positive feedback between bone and pancreatic $\beta$ cells suggested that the low levels of insulin were due to a lack of insulin production by low concentrations of ucOC [6]. To the best of our knowledge, only one recent study has evaluated ucOC in adults with the restrictive and eating/purging types of AN [38]. Conversely to our results, the ucOC levels in Urano's study were found to be overall higher in the AN patients compared with the normal weight controls, but the difference disappeared when only restricted patients were considered [38]. We have no clear arguments to explain the discrepancy 
Table 5 Comparison of parameters in two groups of patients according to the weight change in the last 6 months

\begin{tabular}{|c|c|c|c|}
\hline Parameters & Weight gain $(n=10)$ & Weight loss $(n=34)$ & $\begin{array}{l}p \text { - } \\
\text { values }\end{array}$ \\
\hline Age, years & $18.9 \pm 1.9$ & $17.7 \pm 2.1$ & 0.13 \\
\hline Weight, kg & $43.6 \pm 4.7$ & $41.6 \pm 5.7$ & 0.32 \\
\hline BMI, $\mathrm{kg} / \mathrm{m}^{2}$ & $16.4 \pm 1.3$ & $15.4 \pm 1.9$ & 0.13 \\
\hline Weight 6 months before, $\mathrm{kg}$ & $39.9 \pm 5.6$ & $48.3 \pm 5.8$ & $<0.001$ \\
\hline Weight variation, actual -6 months, $\mathrm{kg}$ & $3.7 \pm 1.6$ & $-7.1 \pm 3.9$ & $<0.001$ \\
\hline Age of AN onset, years & $16.1 \pm 2.2$ & $16.1 \pm 1.7$ & 0.95 \\
\hline Duration of AN, yr & $2.8 \pm 2.5$ & $1.7 \pm 1.1$ & 0.18 \\
\hline Amenorrhoea duration, months & $13.1 \pm 7.9$ & $13.5 \pm 14.2$ & 0.56 \\
\hline $\mathrm{REE}_{\mathrm{m}}, \mathrm{kcal} /$ day & $1054.0 \pm 160.6$ & $962.7 \pm 156.4$ & 0.11 \\
\hline $\mathrm{REE}_{\mathrm{p}}, \mathrm{kcal} /$ day & $1284.5 \pm 48.5$ & $1273.2 \pm 61.4$ & 0.59 \\
\hline Predicted REE values, \% & $-18.2 \pm 10.8$ & $-24.5 \pm 11.0$ & 0.12 \\
\hline WB aBMD, $\mathrm{g} / \mathrm{cm}^{2}$ & $0.994 \pm 0.058$ & $1.046 \pm 0.092$ & 0.07 \\
\hline L1-L4 aBMD, g/cm² & $0.823 \pm 0.080$ & $0.855 \pm 0.108$ & 0.40 \\
\hline Hip aBMD, g/cm² & $0.738 \pm 0.100$ & $0.845 \pm 0.120$ & 0.02 \\
\hline $\mathrm{FN}$ aBMD, $\mathrm{g} / \mathrm{cm}^{2}$ & $0.683 \pm 0.103$ & $0.772 \pm 0.119$ & 0.04 \\
\hline Radius aBMD, $\mathrm{g} / \mathrm{cm}^{2}$ & $0.522 \pm 0.038$ & $0.520 \pm 0.043$ & 0.92 \\
\hline WB FM, kg & $8.0 \pm 3.1$ & $6.6 \pm 2.9$ & 0.18 \\
\hline WB FFST, kg & $34.0 \pm 4.0$ & $33.5 \pm 4.1$ & 0.74 \\
\hline CTX, ng/ml & $0.634 \pm 0.172$ & $0.991 \pm 0.392$ & $<0.01$ \\
\hline PINP, ng/ml & $65.1 \pm 27.1$ & $54.3 \pm 36.0$ & 0.14 \\
\hline $\mathrm{OC}, \mathrm{ng} / \mathrm{ml}$ & $29.1 \pm 11.2$ & $21.9 \pm 9.4$ & 0.05 \\
\hline $\mathrm{ucOC}, \mathrm{ng} / \mathrm{ml}$ & $3.6 \pm 3.1$ & $1.9 \pm 2.2$ & 0.08 \\
\hline Insulin, $\mu \mathrm{U} / \mathrm{ml}$ & $5.7 \pm 3.0$ & $4.5 \pm 3.2$ & 0.16 \\
\hline Leptin, ng/ml & $2.4 \pm 2.5$ & $0.9 \pm 0.7$ & 0.01 \\
\hline Leptin/FM, ng/ml/kg & $0.26 \pm 0.21$ & $0.14 \pm 0.07$ & $<0.01$ \\
\hline sOB-R, ng/ml & $39.2 \pm 9.6$ & $40.6 \pm 13.1$ & 0.76 \\
\hline FLI, & $0.07 \pm 0.07$ & $0.03 \pm 0.02$ & 0.03 \\
\hline Adiponectin, $\mu \mathrm{g} / \mathrm{ml}$ & $22.2 \pm 8.2$ & $18.0 \pm 7.7$ & 0.15 \\
\hline IGF-1, ng/ml & $197.4 \pm 86.7$ & $174.0 \pm 61.5$ & 0.34 \\
\hline
\end{tabular}

Values are presented as mean $\pm \mathrm{SD}$. Only patients with weight variation greater than $1 \mathrm{~kg}$ were included in the analysis. In four patients, the weight was stable and in two others the weight at 6 months was unknown. Finally, 44 patients ( $n=10$ weight gain and $n=34$ weight loss) were included in the final analysis

$B M I$ body mass index, $R E E_{m}$ resting energy expenditure measured, $R E E_{p}$ resting energy expenditure predicted, $a B M D$ areal bone mineral density, $W B$ whole body, $L 1-L 4$ lumbar spine, $F N$ femoral neck, $F M$ fat mass, FFST fat-free soft tissue, CTX type I-C telopeptide breakdown products, PINP procollagen type I N-terminal propeptide, $O C$ osteocalcin, $u c O C$ undercarboxylated $\mathrm{OC}, s O B-R$ soluble leptin receptor, $F L I$ free leptin index defined as leptin/sOB-R ratio, $I G F-1$ insulin-like growth factor-1

between our study and previous works, but the age of the patients and the lack of homogeneity and standardised specificity for commercial assays to detect the ucOC isoform should be considered. In the context of undernutrition, it is interesting to note that $\mathrm{REE}_{\mathrm{m}}$ and $\mathrm{OC}$ were correlated with parameters reflecting glucose homeostasis, suggesting a strong interaction between the skeleton and several tissues associated with energy homeostasis and glucose metabolism.

We confirmed that the low leptin levels in AN are positively correlated with nutritional factors and markers of bone formation (OC, PINP) and negatively correlated with CTX $[10$,
39-46] and sOB-R [36, 44]. sOB-R, the main leptin-binding activity in human blood [47], has generally been found to be higher in AN [36, 44, 48] compared with a healthy population, and this may be a protective mechanism that decreases free leptin bioavailability, further facilitating energy conservation [44]. Our findings also show for the first time that $\mathrm{REE}_{\mathrm{m}}$ is strongly and positively correlated with leptin and FLI and negatively with $s O B-R$, indicating that $R_{m}$ is a surrogate marker to evaluate hormonal changes related to severe undernutrition. In addition, the parameters of glucose homeostasis were strongly and positively correlated with leptin and FLI, 
suggesting that leptin may regulate the amount of insulin secreted [36]. Experimental data have shown that leptin inhibits insulin secretion by regulated osteocalcin activity through sympathetic signalling in osteoblasts [5]. However, as leptin, $\mathrm{OC}$ and insulin resistance were strongly and positively correlated with $\mathrm{REE}_{\mathrm{m}}$, it is more likely that undernutrition was responsible for their concomitant decrease and this adaptation may contribute to preventing exacerbated hypoglycaemia. Conversely, the increase in adiponectin in patients with AN [49] does not seem to interact with glucose homeostasis, but may have a deleterious effect on aBMD at lumbar spine and hip, as previously demonstrated [41].

Bone demineralisation in AN is accentuated with the duration of the disease and amenorrhoea [11, 40]. As aforementioned, a higher aBMD reduction was observed in the chronic compared with the acute group, while no other difference concerning $\mathrm{REE}_{\mathrm{m}}$, bone markers, hormones or body composition was demonstrated. This suggests that major modifications, except those in aBMD, appear rapidly and remain relatively stable at a 'new steady state' in line with the energy metabolic defect. However, disease duration may not be the most pertinent parameter to evaluate the variation in metabolism because body weight, a determinant factor in the regulation of various physiological functions such as reproduction, may frequently change over the course of the illness in AN patients. In this context, we chose to evaluate metabolic adaptations according to the variation in weight (gain or loss) over a short duration of 6 months. Whereas weight, body composition and $\mathrm{REE}_{\mathrm{m}}$ were comparable in patients who gained and lost weight, the patients with weight gain, who had lower aBMD, showed a tendency towards the normalisation of various parameters, such as higher values for OC, leptin and FLI and lower concentrations of CTX, as opposed to the weight loss group. These results suggest that regaining a mean of only $3.7 \mathrm{~kg}$, which corresponds to less than $10 \%$ of body weight, is sufficient to place the patient in a favourable environment and probably reduces the part of spare energy mobilised by the body during chronic starvation [15]. Our results are in line with previous studies reporting the favourable effects on various biological parameters, including adipokines, bone turnover markers and $\mathrm{aBMD}$, when weight or menses is recovered $[14,27,36]$.

Although the number of patients and age-matched controls seemed sufficient to test our hypothesis, this study has some limitations that should be noted. The evaluation of fasting glucose and insulin and the calculation of HOMA-IR are routinely performed to determine glucose homeostasis, but we did not perform oral glucose tolerance tests to verify glucose status. This test may be helpful for monitoring potential OC variations during the glucose tolerance test. Moreover, the cross-sectional design of the study did not allow us to follow the variations in these biological parameters in the patients who had regained or lost body weight. This should be performed in the future. Last, the comparison of patients and controls, some of whom were taking OCPs whereas others were not, may also constitute a limitation because the study design is more complex. Nevertheless, OCPs seem to have only minor effects on bone metabolism.

In conclusion, this study demonstrates important interrelationships between $\mathrm{REE}_{\mathrm{m}}$ and bone remodelling, glucose homeostasis, adipokines and growth factors in AN patients. These findings underscore the importance of preventing energy deficiency in order to limit bone health problems. Moreover, we demonstrated that various biological factors were modulated by the variation in weight over the last 6 months rather than by the disease duration. This finding suggests that weight gain, even minor, sends a positive signal to the organism that probably reduces the measures of spare energy implemented by chronic starvation and tends to normalise various parameters. This response precedes the normalisation of body composition. These data constitute new information about the benefits of early management of AN.

Acknowledgments The authors would like to express their thanks to the patients, the controls and their parents for their participation. This work was supported by the Centre Hospitalier Regional Universitaire (CHRU) of Montpellier (AOI UF 8751 and UF 8854) and a grant from the Société Française d'Endocrinologie Pédiatrique (SFEDP). Some of the biochemical kits were provided by Roche Diagnostics.

Conflicts of interest Laurent Maimoun, Sebastien Guillaume, Patrick Lefebvre, Pascal Philibert, Helena Bertet, Marie-Christine Picot, Laura Gaspari, Françoise Paris, Maude Seneque, Anne-Marie Dupuys, Philippe Courtet, Eric Thomas, Denis Mariano-Goulart, Jacques Bringer, Eric Renard, and Charles Sultan declare that they have no conflict of interest.

\section{References}

1. Ferron M, Lacombe J (2014) Regulation of energy metabolism by the skeleton: osteocalcin and beyond. Arch Biochem Biophys 561C:137-146

2. Karsenty G, Ferron M (2012) The contribution of bone to wholeorganism physiology. Nature 481:314-320

3. Lee NK, Sowa H, Hinoi E, Ferron M, Ahn JD, Confavreux C, Dacquin R, Mee PJ, McKee MD, Jung DY, Zhang Z, Kim JK, Mauvais-Jarvis F, Ducy P, Karsenty G (2007) Endocrine regulation of energy metabolism by the skeleton. Cell 130:456-469

4. Confavreux CB, Levine RL, Karsenty G (2009) A paradigm of integrative physiology, the crosstalk between bone and energy metabolisms. Mol Cell Endocrinol 310:21-29

5. Hinoi E, Gao N, Jung DY, Yadav V, Yoshizawa T, Myers MG Jr, Chua SC Jr, Kim JK, Kaestner KH, Karsenty G (2008) The sympathetic tone mediates leptin's inhibition of insulin secretion by modulating osteocalcin bioactivity. J Cell Biol 183:1235-1242

6. Ferron M, Hinoi E, Karsenty G, Ducy P (2008) Osteocalcin differentially regulates beta cell and adipocyte gene expression and affects the development of metabolic diseases in wild-type mice. Proc Natl Acad Sci U S A 105:5266-5270

7. Fernandez-Real JM, Izquierdo M, Ortega F, Gorostiaga E, GomezAmbrosi J, Moreno-Navarrete JM, Fruhbeck G, Martinez C, Idoate F, Salvador J, Forga L, Ricart W, Ibanez J (2009) The relationship 
of serum osteocalcin concentration to insulin secretion, sensitivity, and disposal with hypocaloric diet and resistance training. J Clin Endocrinol Metab 94:237-245

8. Im JA, Yu BP, Jeon JY, Kim SH (2008) Relationship between osteocalcin and glucose metabolism in postmenopausal women. Clin Chim Acta 396:66-69

9. Kindblom JM, Ohlsson C, Ljunggren O, Karlsson MK, Tivesten A, Smith U, Mellstrom D (2009) Plasma osteocalcin is inversely related to fat mass and plasma glucose in elderly Swedish men. J Bone Miner Res 24:785-791

10. Misra M, Soyka LA, Miller KK, Herzog DB, Grinspoon S, De Chen D, Neubauer G, Klibanski A (2003) Serum osteoprotegerin in adolescent girls with anorexia nervosa. J Clin Endocrinol Metab 88:3816-3822

11. Maimoun L, Guillaume S, Lefebvre P, Philibert P, Bertet H, Picot MC, Gaspari L, Paris F, Courtet P, Thomas E, Mariano-Goulart D, Bringer J, Renard E, Sultan C (2014) Role of sclerostin and Dickkopf-1 in the dramatic alteration in bone mass acquisition in adolescents and young women with recent anorexia nervosa. J Clin Endocrinol Metab 99:E582-E590

12. Faje AT, Fazeli PK, Miller KK, Katzman DK, Ebrahimi S, Lee H, Mendes N, Snelgrove D, Meenaghan E, Misra M, Klibanski A (2014) Fracture risk and areal bone mineral density in adolescent females with anorexia nervosa. Int J Eat Disord 47:458-466

13. Leonard MB, Shults J, Wilson BA, Tershakovec AM, Zemel BS (2004) Obesity during childhood and adolescence augments bone mass and bone dimensions. Am J Clin Nutr 80:514-523

14. Hotta M, Fukuda I, Sato K, Hizuka N, Shibasaki T, Takano K (2000) The relationship between bone turnover and body weight, serum insulin-like growth factor (IGF) I, and serum IGF-binding protein levels in patients with anorexia nervosa. J Clin Endocrinol Metab 85:200-206

15. Kosmiski L, Schmiege SJ, Mascolo M, Gaudiani J, Mehler PS (2014) Chronic starvation secondary to anorexia nervosa is associated with an adaptive suppression of resting energy expenditure. $\mathbf{J}$ Clin Endocrinol Metab 99:908-914

16. Auwerx J, Staels B (1998) Leptin. Lancet 351:737-742

17. Ducy P, Amling M, Takeda S, Priemel M, Schilling AF, Beil FT, Shen J, Vinson C, Rueger JM, Karsenty G (2000) Leptin inhibits bone formation through a hypothalamic relay: a central control of bone mass. Cell 100:197-207

18. Elefteriou F, Takeda S, Ebihara K, Magre J, Patano N, Kim CA, Ogawa Y, Liu X, Ware SM, Craigen WJ, Robert JJ, Vinson C, Nakao K, Capeau J, Karsenty G (2004) Serum leptin level is a regulator of bone mass. Proc Natl Acad Sci U S A 101:3258-3263

19. Yadav VK, Oury F, Suda N, Liu ZW, Gao XB, Confavreux C, Klemenhagen KC, Tanaka KF, Gingrich JA, Guo XE, Tecott LH, Mann JJ, Hen R, Horvath TL, Karsenty G (2009) A serotonindependent mechanism explains the leptin regulation of bone mass, appetite, and energy expenditure. Cell 138:976-989

20. Theintz G, Buchs B, Rizzoli R, Slosman D, Clavien H, Sizonenko PC, Bonjour JP (1992) Longitudinal monitoring of bone mass accumulation in healthy adolescents: evidence for a marked reduction after 16 years of age at the levels of lumbar spine and femoral neck in female subjects. J Clin Endocrinol Metab 75:1060-1065

21. Hernandez CJ, Beaupre GS, Carter DR (2003) A theoretical analysis of the relative influences of peak BMD, age-related bone loss and menopause on the development of osteoporosis. Osteoporos Int 14:843-847

22. Garcia FD, Grigioni S, Chelali S, Meyrignac G, Thibaut F, Dechelotte P (2010) Validation of the French version of SCOFF questionnaire for screening of eating disorders among adults. World J Biol Psychiatry 11:888-893

23. Sheehan DV, Lecrubier Y, Sheehan KH, Amorim P, Janavs J, Weiller E, Hergueta T, Baker R, Dunbar GC (1998) The MiniInternational Neuropsychiatric Interview (M.I.N.I.): the development and validation of a structured diagnostic psychiatric interview for DSM-IV and ICD-10. J Clin Psychiatry 59(Suppl 20): 22-33, quiz 34-57

24. Roza AM, Shizgal HM (1984) The Harris Benedict equation reevaluated: resting energy requirements and the body cell mass. Am J Clin Nutr 40:168-182

25. Kratzsch J, Lammert A, Bottner A, Seidel B, Mueller G, Thiery J, Hebebrand J, Kiess W (2002) Circulating soluble leptin receptor and free leptin index during childhood, puberty, and adolescence. J Clin Endocrinol Metab 87:4587-4594

26. Biller BM, Saxe V, Herzog DB, Rosenthal DI, Holzman S, Klibanski A (1989) Mechanisms of osteoporosis in adult and adolescent women with anorexia nervosa. J Clin Endocrinol Metab 68: 548-554

27. Klibanski ABB, Schoenfeld DA, Herzog DB, Saxe VC (1995) The effects of estrogen administration on trabecular bone loss in young women with anorexia nervosa. J Clin Endocrinol Metab 80:898904

28. Kooh SW, Noriega E, Leslie K, Muller C, Harrison JE (1996) Bone mass and soft tissue composition in adolescents with anorexia nervosa. Bone 19:181-188

29. Heaney RP, Abrams S, Dawson-Hughes B, Looker A, Marcus R, Matkovic V, Weaver C (2000) Peak bone mass. Osteoporos Int 11: 985-1009

30. Ravussin E, Lillioja S, Anderson TE, Christin L, Bogardus C (1986) Determinants of 24-hour energy expenditure in man. Methods and results using a respiratory chamber. J Clin Invest 78 : 1568-1578

31. Ferron M, McKee MD, Levine RL, Ducy P, Karsenty G (2012) Intermittent injections of osteocalcin improve glucose metabolism and prevent type 2 diabetes in mice. Bone 50:568-575

32. Zhou B, Li H, Xu L, Zang W, Wu S, Sun H (2013) Osteocalcin reverses endoplasmic reticulum stress and improves impaired insulin sensitivity secondary to diet-induced obesity through nuclear factor-kappaB signaling pathway. Endocrinology 154:1055-1068

33. Ferron M, Wei J, Yoshizawa T, Del Fattore A, DePinho RA, Teti A, Ducy P, Karsenty G (2010) Insulin signaling in osteoblasts integrates bone remodeling and energy metabolism. Cell 142:296-308

34. Fulzele K, Riddle RC, DiGirolamo DJ, Cao X, Wan C, Chen D, Faugere MC, Aja S, Hussain MA, Bruning JC, Clemens TL (2010) Insulin receptor signaling in osteoblasts regulates postnatal bone acquisition and body composition. Cell 142:309319

35. Bluher M, Michael MD, Peroni OD, Ueki K, Carter N, Kahn BB, Kahn CR (2002) Adipose tissue selective insulin receptor knockout protects against obesity and obesity-related glucose intolerance. Dev Cell 3:25-38

36. Misra M, Miller KK, Almazan C, Ramaswamy K, Aggarwal A, Herzog DB, Neubauer G, Breu J, Klibanski A (2004) Hormonal and body composition predictors of soluble leptin receptor, leptin, and free leptin index in adolescent girls with anorexia nervosa and controls and relation to insulin sensitivity. J Clin Endocrinol Metab 89:3486-3495

37. Ostrowska Z, Ziora K, Oswiecimska J, Swietochowska E, Szapska B, Wolkowska-Pokrywa K, Dyduch A (2012) RANKL/RANK/ OPG system and bone status in females with anorexia nervosa. Bone 50:156-160

38. Urano A, Hotta M, Ohwada R, Araki M (2014) Vitamin K deficiency evaluated by serum levels of undercarboxylated osteocalcin in patients with anorexia nervosa with bone loss. Clin Nutr S02615614

39. Grinspoon SBH, Lee K, Anderson E, Herzog D, Klibanski A (1996) Effects of short-term recombinant human insulin-like 
growth factor I administration on bone turnover in osteopenic women with anorexia nervosa. J Clin Endocrinol Metab 81:3864-3870

40. LA Soyka GS, Levitsky LL, Herzog DB, Klibanski A (1999) The effects of anorexia nervosa on bone metabolism in female adolescents. J Clin Endocrinol Metab 84:4489-4496

41. Misra M, Miller KK, Cord J, Prabhakaran R, Herzog DB, Goldstein M, Katzman DK, Klibanski A (2007) Relationships between serum adipokines, insulin levels, and bone density in girls with anorexia nervosa. J Clin Endocrinol Metab 92:2046-2052

42. Misra M, Miller KK, Stewart V, Hunter E, Kuo K, Herzog DB, Klibanski A (2005) Ghrelin and bone metabolism in adolescent girls with anorexia nervosa and healthy adolescents. J Clin Endocrinol Metab 90:5082-5087

43. Tagami T, Satoh N, Usui T, Yamada K, Shimatsu A, Kuzuya H (2004) Adiponectin in anorexia nervosa and bulimia nervosa. J Clin Endocrinol Metab 89:1833-1837

44. Housova J, Anderlova K, Krizova J, Haluzikova D, Kremen J, Kumstyrova T, Papezova H, Haluzik M (2005) Serum adiponectin and resistin concentrations in patients with restrictive and binge/ purge form of anorexia nervosa and bulimia nervosa. J Clin Endocrinol Metab 90:1366-1370
45. Haluzikova D, Dostalova I, Kavalkova P, Roubicek T, Mraz M, Papezova H, Haluzik M (2009) Serum concentrations of adipocyte fatty acid binding protein in patients with anorexia nervosa. Physiol Res 58:577-581

46. Legroux-Gerot I, Vignau J, Biver E, Pigny P, Collier F, Marchandise X, Duquesnoy B, Cortet B (2010) Anorexia nervosa, osteoporosis and circulating leptin: the missing link. Osteoporos Int 21:1715-1722

47. Chan JL, Bluher S, Yiannakouris N, Suchard MA, Kratzsch J, Mantzoros CS (2002) Regulation of circulating soluble leptin receptor levels by gender, adiposity, sex steroids, and leptin: observational and interventional studies in humans. Diabetes 51:21052112

48. Krizova J, Papezova H, Haluzikova D, Parizkova J, Jiskra J, Kotrlikova E, Haas T, Haluzik M (2002) Soluble leptin receptor levels in patients with anorexia nervosa. Endocr Res 28: 199-205

49. Pannacciulli N, Vettor R, Milan G, Granzotto M, Catucci A, Federspil G, De Giacomo P, Giorgino R, De Pergola G (2003) Anorexia nervosa is characterized by increased adiponectin plasma levels and reduced nonoxidative glucose metabolism. J Clin Endocrinol Metab 88:1748-1752 